\title{
A new reference electrode for electrochemistry in pyridine
}

Numerous reference electrodes are available for aqueous electrochemistry, whereas very few examples have been reported for use in individual nonaqueous systems $^{1}$. In pyridine, the choice is restricted to the $\mathrm{Ag} / \mathrm{AgNO}$ ( $.0 M$ ) electrode (NAgE) ${ }^{2,3}$, $\mathrm{Zn}(\mathrm{Hg}) \mid \mathrm{ZnCl}$ (s) electrode ${ }^{4}$, or various types of aqueous reference electrodes combined with an aqueous-nonaqueous liquid junction. Use of the latter electrodes often contaminates anliydrous solutions with water.

The potential of a freshly prepared NAgE vs. an aqueous saturated calomel electrode (S.C.E.) has recently been shown ${ }^{5}$ to be $70 \pm 10 \mathrm{mV}$, which value is slightly smaller than the $90 \mathrm{mV}$ previously reported ${ }^{3}$. Study of several NAgE electrodes shoved that an aging process (probably loss of silver nitrate) causes the potential to decrease slowly, e.g., after ca. 4 months the potential is $-3 \mathrm{mV}$ vs. S.C.E. Because of the scatter of the NAgE potential, a new reference electrode was sought.

In an investigation of the kinetics of the electrochemical reduction of copper(II) in pyridine, BOCHKov AND GORBACHEV" suggested that the redox couple $\mathrm{Cu}(\mathrm{I}) / \mathrm{Cu}(\mathrm{II})$ in pyridine-might serve as a reference electrode. Four reference electrodes involving this couple have been evaluated; the most stable and reproducible example is described.

\section{Experimental}

The reference electrode solution is a pyridine solution of $2.5 \mathrm{~m} M$ copper(I) chloride, $25 \mathrm{~m} M$ copper(II) chloride and o.I $M$ tetraethylammonium chloride, prepared from anhydrous salts. This solution is separated from the working electrode compartment by a glass frit and a plug of $0.1 M$ tetraethylammonium perchloratepyridine-6\% methyl cellulose gel. The electrode is a $2-\mathrm{cm}^{2}$ platinum sheet.

Equilibrium potentials of the electrode were measured by a Leeds \& Northrup pH meter and polarograms were recorded with a Leeds $\&$ Northrup Type E ElectroChemograph equipped with an operational amplifier-based IR-compensator?.

\section{Results and discussion}

Potential measurements on the copper reference electrode vs. S.C.E. over a period of 5 days showed no drift and only small experimental scatter; the mean value and range were $3 \pm 2 \mathrm{mV}$. After 5 days, a very slow drift to more negative potential occurred, probably owing to loss of copper salts through the plug and frit. The potential of this electrode should, however, be less dependent on loss of electrolyte than the NAgE because the potential is determined by the ratio of the redox constituents, which is likely to remain relatively constant during diffusive concentration depletion. Nevertheless, for accurate work, the solution in the reference electrode compartment should be replenished at least once a week.

Microscale polarization experiments showed that, after $30 \mathrm{sec}$ of polarization at $20 \mu \mathrm{A} \mathrm{cm}^{-1}$, the equilibrium potential is regained in $60 \mathrm{sec}$. Consequently, when the electrode is used in a three-electrode configuration ${ }^{8}$ with IR compensation, no significant polarization will occur.

A polarogram of $1.2 \mathrm{~m} M$ sodium perchlorate in o.I $M$ tetraethylammonium 
perchlorate had an $E_{1}$ value of $-1.842 \mathrm{~V}$ with the potential scale referred to the $\mathrm{Cu}(\mathrm{I}) / \mathrm{Cu}(\mathrm{II})$ redox potential, compared with $-\mathrm{I} .889 \mathrm{~V}$ vs. NAgE, a shift of $47 \mathrm{mV}$. Computation of the potential shift from the values of the two reference electrode potentials $v$ s. S.C.E. suggests that the difference should be $67 \mathrm{mV}$. However, this calculation ignores liquid junction potentials; for direct correlation of reference potentials, the salt-bridge connection should be made with the polarographic solution used in the half-wave potential measurements". With this intermediate salt-bridge, the experimental potential difference is $47 \mathrm{mV}$, which agrees with the difference in $E_{\text {, value. }}$

In conclusion, the pyridine $\mathrm{Cu}(\mathrm{I}) / \mathrm{Cu}$ (II) reference electrode is a stable, reproducible reference electrode with a potential (liquid junction potential included) close to that of the aqueous S.C.E.

The authors thank the National Science Foundation and Petroleum Research fiund of the American Chemical Society, which helped support the work described.

Department of Chemistry,

JOFin BROALHEAT

University of Michigan, PHILIP J. ElVING

Ann Arbor, Mich. 48504 (U.S.A.)

I D.J.G. IVIES ANDG.J.JANZ (Editors), Reference Eleclyodes: Theory and Pruclice, Academic I'ress, New York, 1961.

2 U. Bretrocci, Z. Elehtrochem., GI (19.57) $43 \mathrm{I}$.

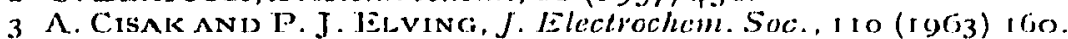

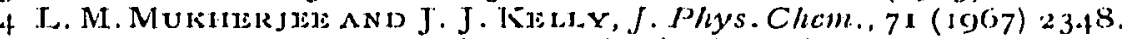

5 J. BROADHIEAD AND I'. J. BEvINC, Aual. Chem., in press.

G Y. G. BOChkov and S. V. Gorbachiev, Russian.J. Phys. Chem., 40 (1960) 393.

7 R. ANNINO AND KS. J. HAGLiER, Anal.Chem.. 35 (I963) I 555.

8 J. IE. HICKEY, M. S. SPRITZER AND J'J JELVING, Anal.Chim. Acta, 35 (1906) 277.

9 IJ. Tsuj and P. J. Iilving, Anal, Chim., \& I (rgog) 2 ig.

(Received August 28th, r969)

Anal. Chim. Acta, 48 (1909) 433-434

\section{Errors in the use of volumetric flasks for extraction in atomic absorption spectroscopy}

Extraction of metals as their complexes into organic solvents as a means of sensitivity enhancement has been widely adopted in atomic absorption spectroscopy. In many laboratories where routine trace element analyses are to be carried out, it has become a common practice, in order to facilitate extractions, to put the aqueous sample (IO0-I50 ml) in a volumetric flask $(200-250 \mathrm{ml})$ or in a Babcock bottle1.2 with the organic solvent and chelating agent and to carry out the extraction in these containers. When the extraction is finished, distilled water is added to these vessels to bring the organic phase to the narrow necks thus enabling direct and convenient aspiration without using a separatory funnel to separate the organic phase.

However, if ca. roo $\mathrm{ml}$ of distilled water passes through the organic layer which has already attained equilibrium with its underlying aqueous layer, then one or both of the following effects may be expected. ( $I$ ) Some organic solvent can dissolve 